\title{
Laboratory diagnosis of mumps in a partially immunized population: The Nova Scotia experience
}

\author{
TF Hatchette $\mathrm{MD}^{1,2}$, R Davidson $\mathrm{PhD}^{1,3}$, S Clay $\mathrm{MSc}^{4}$, J Pettipas $\mathrm{BSc}^{1}$, J LeBlanc $\mathrm{PhD}^{1}$, \\ S Sarwal $M D^{5,6}, M$ Smieja $M D P h D^{7}$, KR Forward $M D^{1,2}$
}

TF Hatchette, R Davidson, S Clay, et al. Laboratory diagnosis of mumps in a partially immunized population: The Nova Scotia experience. Can J Infect Dis Med Microbiol 2009;20(4):e157-e162.

BACKGROUND: In 2007, Atlantic Canada experienced a large outbreak of mumps predominately in university students who had received a single dose of measles, mumps and rubella vaccine. The present study describes the performance characteristics of reverse transcriptase polymerase chain reaction (RT-PCR) on buccal and urine specimens and immunoglobulin M (IgM) serology in this partially immune population.

METHODS: Patients presenting with symptoms suspicious for mumps had a serum, urine and a buccal swab collected for diagnostic testing. Persons were classified as a 'confirmed' case according to the Public Health Agency of Canada's definition. Sera were tested using an enzyme-linked immunoassay. Detection of mumps virus in buccal swabs and urine samples was performed by RT-PCR.

RESULTS: A subset of 155 cases and 376 non-cases that had all three specimens submitted was used for calculating the performance characteristics. The sensitivity of RT-PCR on buccal swabs, urine specimens and IgM serology were 79\%, 43\% and 25\%, respectively. The specificity of RT-PCR on buccal swabs, urine specimens and IgM serology was $99.5 \%, 100 \%$ and $99.7 \%$, respectively. Only 12 of 134 (9\%) patients had positive urine specimens in the presence of negative oral swabs. CONCLUSION: RT-PCR on buccal swabs is the ideal specimen for diagnosis. Testing an additional urine sample in an outbreak setting did not increase the diagnostic yield significantly, but doubled testing volume and cost. In addition, the data suggest that, in this partially immune group, IgM serology has little value in the diagnosis of acute infection.

Key Words: Canada; Latent class modeling; Mumps; Nucleic acid testing; RT-PCR; Sensitivity; Serology; Specificity
Diagnostic des oreillons en laboratoire chez une population partiellement immunisée : Expérience néo-écossaise

HISTORIQUE : En 2007, les provinces de l'Atlantique ont connu une importante éclosion d'oreillons, surtout chez des étudiants universitaires qui avaient reçu une seule dose du vaccin contre la rougeole, les oreillons et la rubéole. La présente étude décrit les caractéristiques de rendement du test RT-PCR (réaction en chaîne de la polymérase par transcriptase inverse) appliqué à des spécimens de salive et d'urine et celles du dosage de l'immunoglobuline M (IgM) chez cette population partiellement immunisée.

MÉTHODES : Des patients présentant des symptômes d'oreillons ont subi des prélèvements sériques, urinaires et salivaires pour analyses diagnostiques. Ils ont été classés parmi les cas " confirmés » selon la définition de l'Agence de santé publique du Canada. Les échantillons sériques ont été testés par dosage immuno-enzymatique. Le dépistage du virus des oreillons dans les spécimens de salive et d'urine a été effectué par RT-PCR.

RÉSULTATS : Un groupe de 155 cas et 376 «non-cas » ayant soumis les trois types de spécimens ont servi au calcul des caractéristiques de rendement. La sensibilité de la RT-PCR appliquée aux spécimens de salive et d'urine et celle du dosage sérologique de l'IgM ont été de $79 \%, 43 \%$ et $25 \%$, respectivement. La spécificité de la RT-PCR appliquée aux spécimens de salive et d'urine et celle du dosage sérologique de l'IgM ont été de 99,5\%, $100 \%$ et $99,7 \%$, respectivement. Seulement 12 patients sur 134 (9\%) ont présenté des spécimens d'urine positifs en présence de spécimens salivaires négatifs.

CONCLUSIONS : La RT-PCR appliquée aux spécimens de salive est le test diagnostique idéal. L'analyse d'un échantillon urinaire additionnel lors d'une éclosion n'a pas significativement augmenté le rendement diagnostique, mais a doublé le volume et le coût des tests. De plus, selon les données, chez ce groupe partiellement immunisé, le dosage sérologique de l'IgM est peu utile au diagnostic de l'infection aiguë. lthough rates of endemicity vary among countries, mumps
is a vaccine-preventable disease that is endemic worldwide. Before vaccination, epidemics occurred predominately in fiveto nine-year-old children every two to five years. $(1,2)$. Since 1969 , routine vaccination has resulted in a greater than $99 \%$ decline in the number of cases reported in the United States (US) and Canada (1,3). Despite universal vaccination programs, outbreaks continue to occur. Between 2004 and 2006, more than 56,000 cases occurred in the United Kingdom (UK) in predominately unvaccinated individuals (4). In 2006, 6584 cases of mumps were reported in the US, mostly in university students. Of those with known vaccination status, $63 \%$ of cases had received two doses of mumps-containing vaccine (5). Between 1999 and 2004, only three cases of mumps were reported to the Department of Health in Nova Scotia (NS). In 2005, there were 32 cases in two clusters of adolescents and young adults. The mumps virus isolated from these patients was linked to the strain circulating in the UK at the same time (6).

In February 2007, mumps re-emerged in university students. We requested that physicians submit a buccal swab and urine for polymerase chain reaction (PCR)-based viral detection and serum for antibody determination. We report the performance characteristics of these diagnostic methods and provide recommendations for future use.

${ }^{1}$ Division of Microbiology, Department of Pathology and Laboratory Medicine, Queen Elizabeth II Health Sciences Centre; ${ }^{2}$ Dalhousie University,

Department of Pathology; ${ }^{3}$ Dalhousie University, Department of Microbiology and Immunology; ${ }^{4}$ Canadian Field Epidemiology Program, Public

Health Agency of Canada; ${ }^{5}$ Nova Scotia Department of Health Promotion and Protection; ${ }^{6}$ Dalhousie University, Department of Community

Health and Epidemiology; ${ }^{7}$ Department of Pathology and Molecular Medicine, McMaster University, Hamilton

Correspondence: Dr Todd F Hatchette, Division of Microbiology, QEII Health Sciences Centre, 5788 University Avenue, Room 315, Halifax,

Nova Scotia B3H 1V8. Telephone 902-473-6885, fax 902-473-7971, e-mail todd.hatchette@cdha.nshealth.ca 


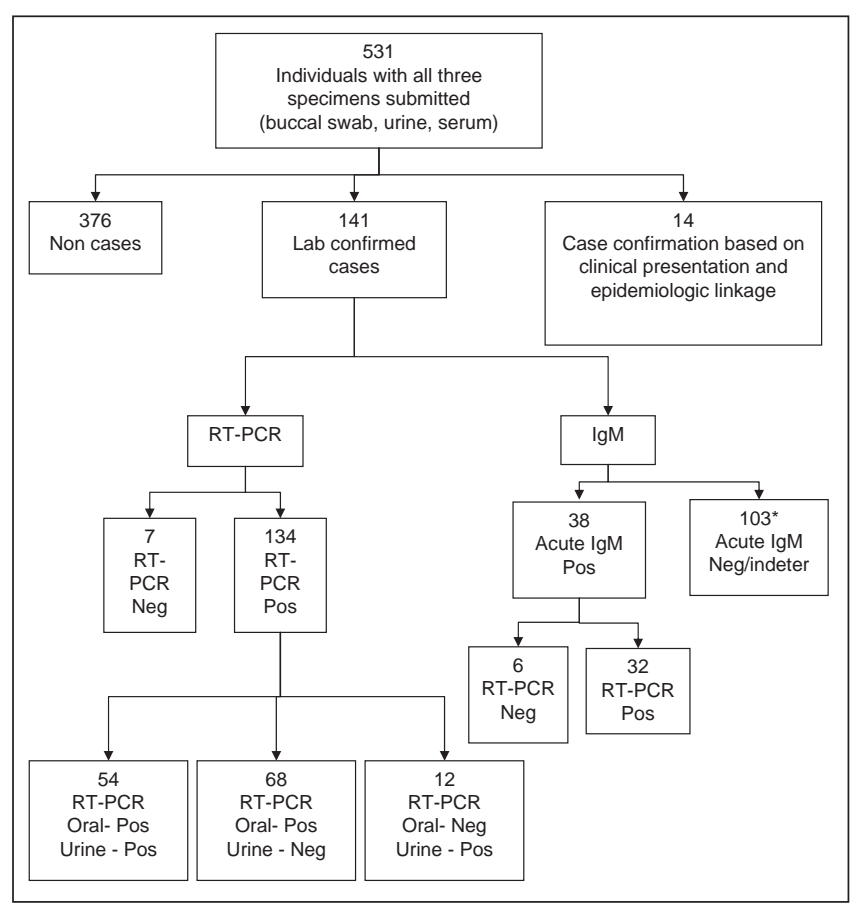

Figure 1) Distribution of test results of cases and non-cases used when determining the performance characteristics. *Only 24 convalescent sera available for testing. One additional case was confirmed based detection of immunoglobulin M (IgM) antibodies in convalescent serum. Indeter Indeterminate; Neg Negative; Pos Positive; RT-PCR Reverse transcriptase polymerase chain reaction

\section{METHODS}

\section{Participants}

Patients presenting to NS physicians with symptoms suggestive of mumps infection between February and July 2007 were eligible for inclusion in the analysis. Physicians were instructed to collect three specimens for diagnosis: blood for serology, a buccal swab and a urine specimen for detection of mumps by reverse transcriptase PCR (RT-PCR). Physicians were educated on the appropriate collection of buccal swabs based on the Center for Disease Control and Prevention (Atlanta) guidelines (7). Buccal swabs were placed in universal transport media (UTM-RT; Copan Diagnostics, USA) and transported to the microbiology laboratory at the Queen Elizabeth II Health Sciences Centre, Halifax, NS. Urine was collected in sterile containers. Specimens were refrigerated on receipt and tested within $12 \mathrm{~h}$. A laboratory requisition provided to physicians was designed specifically for this outbreak to collect a standardized data set including symptoms, time from symptom onset, history of exposure and vaccination status.

Persons were classified using the Public Health Agency of Canada's (PHAC) national case definition (8). A 'laboratoryconfirmed' case is a patient in whom mumps-specific immunoglobulin (Ig) M antibody is detected or mumps virus identified by RT-PCR. In the absence of definitive laboratory findings, such patients were deemed as 'confirmed' mumps cases if they presented with evidence of parotitis and had a confirmed epidemiological link to a laboratory-confirmed case. Those patients who did not fit this case definition were considered non-cases.

\section{Serology}

Sera were tested using a commercially available IgG and IgM enzyme immunoassay (EIA) (Enzygnost, Dade Behring, USA). Testing was performed in accordance with the manufacturer's instructions using an automated analyzer (Triturus, Somagen Diagnostics Inc, Canada). The IgM EIA included an IgG absorption step that removed competing IgG antibody and reduced interference by rheumatoid factor. Serology results were categorized as negative, indeterminate or positive in accordance with the manufacturer's instructions. Only IgM results of acute sera were used to calculate sensitivity of this test because convalescent sera were only available in a subset of the eligible patients, and using results from the few convalescent samples would introduce considerable bias.

\section{RT-PCR}

Nucleic acid testing by RT-PCR, using a previously described hemi-nested protocol directed at the $\mathrm{SH}$ gene, was used to detect mumps virus in buccal and urine samples (9). Ten millilitres of urine was centrifuged at $3000 \mathrm{~g}$ for $10 \mathrm{~min}$ before processing. The resulting concentrated pellet was resuspended in $1 \mathrm{~mL}$ of urine, which was used for extraction. Viral RNA was extracted manually using QIAmp Viral RNA Mini Kit (Qiagen, Canada) or on the MagNa Pure automated platform (Roche Diagnostics, Germany) using the MagNA Pure LC total nucleic acid isolation kits (Roche Diagnostics, Germany) as per the manufacturer's protocol. Amplified products were resolved by acrylamide gel electrophoresis and ethidium bromide staining. Although the assay does not include an internal amplification control, a subset of specimens were subdivided to which a positive mumps virus from culture was seeded to one portion as an amplification control.

\section{Statistics}

The PHAC case definition was used as the reference standard to which the result of each diagnostic tests were compared. A $2 \times 2$ table was constructed to determine the sensitivity, specificity, and positive and negative predictive values, as well as associated confidence intervals in this population. Latent class modelling, a novel statistical method for calculating diagnostic test characteristics without an explicit reference standard, was used to calculate sensitivity and specificity. Statistical analysis including frequencies, confidence intervals (binomial exact) and significance testing were performed using Stata (Intercooled 8, Stata Corporation, USA). Latent class modelling was performed using Latent Gold 3.0 (Statistical Innovations Inc, USA).

\section{RESULTS}

In total, 531 patients had all three specimens (buccal swab, urine and serum) submitted. The analysis was conducted on this core group of 155 cases and 376 non-cases (Figure 1). Eighty-nine per cent of cases (141 patients) were laboratory confirmed and 14 were clinically confirmed. General characteristics between the two groups were the same except the median age was higher in the non-cases (23 years versus 27.5 years; $\mathrm{P}=0.0001$ ).

\section{Serology}

Of the 141 laboratory-confirmed cases, 38 (27.0\%) had a positive IgM result. Laboratory confirmation was based solely on positive IgM serology in only seven cases. Six of these seven 
cases were identified with the initial sample at the time of presentation, whereas one case was identified from IgM antibodies detected in a convalescent sample (Figure 1). The median age of these six cases ( 48 years; range 22 to 64 years) was significantly higher than the median age of the PCR-confirmed cases (23 years; range 13 to 63 years) $(\mathrm{P}<0.006)$. The median time from the onset of symptoms to IgM serum collection was four days.

Follow-up sera were requested for re-testing for IgM antibody to mumps from 25 cases initially negative for this analyte. Of these, mumps was detected in 24 by the RT-PCR assay. Four of these patients had IgM detected on the follow-up sera. A single case, who did not have mumps detected by RT-PCR, was diagnosed based on a positive IgM test in follow-up sera.

Vaccination status was determined by asking whether individuals recalled having a mumps-containing vaccine in the past. Only 260 of 531 patients could recall whether they had received the vaccine. Of these, 216 remembered having received vaccine and $44 \mathrm{did}$ not. Of the laboratory-confirmed cases, five of eight (62\%) who did not recall receiving the vaccine had detectable IgM antibodies to mumps compared with 17 of 75 laboratory-confirmed cases who remembered having the vaccine.

Eighty-eight per cent of the mumps cases (136 of 155) had positive IgG serology compared with 69\% (256 of 369) of the non-cases (seven sera had insufficent volume to complete IgG testing).

\section{RT-PCR testing}

Seventy-four per cent of buccal and urine RT-PCR specimens submitted were collected within four days of symptom onset. The median time from symptom onset to testing was two days for urine and buccal swabs; however, mumps virus RNA could be detected from buccal swabs and urine up to nine and seven days, respectively, after symptom onset. Of those who had both buccal and urine specimens collected on the day of presentation, only 12 patients had a positive urine PCR test when the buccal swab was negative. The median time from symptom onset to the collection of these urine specimens was three days (range one to seven days).

Phylogenetic analysis comparing the $\mathrm{SH}$ gene sequence of the viruses identified in patient samples during this outbreak showed that the virus responsible for this outbreak belonged to genotype $\mathrm{G}$ and is identical to the viruses that circulated in previous outbreaks in Nova Scotia, the US and the UK $(6,10)$.

A subset of the total number of specimens submitted for RT-PCR testing was subdivided into which a positive mumps virus from culture was seeded to one portion as an amplification control. Only one of 164 buccal samples failed to amplify, suggesting the presence of PCR inhibitors. The inhibitory rate in urine samples was $5 \%$ (21 of 400$)$. However, because this approach essentially doubles the cost and time required for testing, duplicate testing was abandoned when the demand for testing overwhelmed the surge capacity of the laboratory.

\section{Performance characteristics of serology and RT-PCR}

The performance characteristics of the different testing methods are outlined in Tables 1 to 3. Two patients whose specimens were positive by the RT-PCR assay and one patient whose blood was positive for mumps-specific IgM were categorized as 'non-mumps' cases. These individuals were assessed by public
TABLE 1

Results of reverse transcriptase polymerase chain reaction (RT-PCR) testing of buccal swabs, urine samples and immunoglobulin M (IgM) serology using the Public Health Agency of Canada definition of confirmed cases as the reference standard

\begin{tabular}{lcc}
\hline & Confirmed cases & Non-cases \\
\hline Buccal swab RT-PCR positive & 122 & 2 \\
Buccal swab RT-PCR negative & 33 & 374 \\
Urine RT-PCR positive & 66 & 0 \\
Urine RT-PCR negative & 89 & 376 \\
IgM positive & 38 & 1 \\
IgM negative & 117 & 375 \\
\hline
\end{tabular}

health practitioners and were determined to have neither symptoms consistent with mumps nor clear linkages to cases of mumps. Although their test results were considered non-cases by public health and for the purpose of the analysis were considered false positives, both RT-PCR specimens tested positive using a second method directed at a different region of the genome (F gene), suggesting that they are real cases but had an atypical presentation.

Latent class modelling was also used to calculate the sensitivity and specificity of IgM results or PCR on buccal or urine specimens without reference to an explicit gold standard. Latent class, two-cluster models were separately calculated under two assumptions: model 1, in which indeterminate results were treated as negative; and model 2 , in which such results were interpreted as positive (Table 3). Both latent class models showed very high sensitivity for buccal swabs $(87.1 \%$ to $88.3 \%$ ) with good specificity (greater than 94\%). Urine had lower sensitivity (55.2\% to $63.3 \%$ ), whereas IgM serology had poor sensitivity $(35.2 \%$ to $42.4 \%)$. Adjusting the latent class models for age and unilateral/bilateral swelling gave similar results with sensitivity estimates of $1 \%$ to $3 \%$ lower than in the unadjusted models (data not shown).

\section{DISCUSSION}

We describe the performance characteristics of IgM serology and RT-PCR on urine and buccal swabs in the context of a large mumps outbreak in a partially immunized population.

Although the correlation of EIA testing and presence of neutralizing antibodies may be less than optimal, our findings suggest that our population is only partially immune (11). In addition to the data presented here, a separate serosurvey of predominately health care workers showed that only $74 \%$ had IgG antibodies against mumps. Because there is no central record of immunizations in NS, it is impossible to correlate our findings with immunization records. However, other studies suggest that waning immunity may contribute to outbreaks in older vaccinated populations (12).

We demonstrate that RT-PCR, particularly when performed on buccal swabs, is the most sensitive diagnostic test for mumps. RT-PCR methods have a number of advantages over conventional culture, including increased sensitivity and faster turn-around time. As well, they are not dependent on the viability of the virus and less dependent on conditions of specimen handling and transport $(13,14)$. Similar to others, we found that that the ability to detect virus in specimens that were previously frozen is not decreased (data not shown) 
TABLE 2

Overall performance characteristics of reverse transcriptase polymerase chain reaction (RT-PCR) and immunoglobulin M (IgM) serology using the Public Health Agency of Canada definition of confirmed cases as the reference standard

\begin{tabular}{|c|c|c|c|c|c|c|}
\hline & $\begin{array}{c}\text { Sensitivity, \% } \\
(95 \% \mathrm{Cl})\end{array}$ & $\begin{array}{l}\text { Specificity, \% } \\
(95 \% \mathrm{Cl})\end{array}$ & $\begin{array}{l}\text { Positive predictive } \\
\text { value, } \%(95 \% \mathrm{Cl})\end{array}$ & $\begin{array}{l}\text { Negative predictive } \\
\text { value, } \%(95 \% \mathrm{CI})\end{array}$ & $\begin{array}{c}\text { Accuracy, \% } \\
(95 \% \mathrm{Cl})\end{array}$ & $\begin{array}{l}\text { Likelihood ratio of a } \\
\text { positive result } \\
(95 \% \mathrm{Cl})\end{array}$ \\
\hline $\begin{array}{l}\text { Buccal swab } \\
\text { RT-PCR }\end{array}$ & 78.7 (71.4-84.9) & 99.5 (98.1-99.9) & $98.4(94.3-99.8)$ & $91.9(88.8-94.4)$ & $93.4(91.0-95.4)$ & $148(37.6-849.0)$ \\
\hline Urine RT-PCR & $42.6(34.7-50.8)$ & 100 & 100 & $80.9(77.0-84.3)$ & 83.2 (79.8-86.3) & * \\
\hline IgM serology & $24.5(18.0-32.1)$ & 99.7 (98.5-100) & $97.4(86.5-99.9)$ & 76.2 (72.2-79.9) & $77.8(74.0-81.2)$ & $92.2\left(12.1-^{*}\right)$ \\
\hline
\end{tabular}

*Not calculable

TABLE 3

Calculated performance characteristics of the different diagnostic methods using latent class modelling (Latent Gold 3.0) or Public Health Agency of Canada (PHAC) definition of mumps

\begin{tabular}{|c|c|c|c|c|c|c|}
\hline & \multicolumn{2}{|c|}{$\begin{array}{c}\text { Latent class model } 1 \\
\text { (Indeterminate }=\text { negative) }\end{array}$} & \multicolumn{2}{|c|}{$\begin{array}{c}\text { Latent class model } 2 \\
\text { (Indeterminate }=\text { positive) }\end{array}$} & \multicolumn{2}{|c|}{ PHAC case definition } \\
\hline & Sensitivity, \% & Specificity, \% & Sensitivity, \% & Specificity, \% & Sensitivity, \% & Specificity, \% \\
\hline Buccal swab & 88.3 & 97.8 & 87.1 & 94.1 & 78.7 & 99.5 \\
\hline Urine & 63.3 & 100.0 & 55.2 & 99.0 & 42.6 & 100 \\
\hline $\begin{array}{l}\text { Immunoglobulin M } \\
\text { serology }\end{array}$ & 35.2 & 99.6 & 42.4 & 95.6 & 24.5 & 99.7 \\
\hline
\end{tabular}

$(14,15)$. Why the sensitivity of RT-PCR on buccal swabs was only $79 \%$ is not clear, because the majority of specimens were collected at a time when there should have been maximal viral shedding. The sensitivity of RT-PCR can be affected by inhibition; however, a documented inhibitory rate of $5 \%$ for urine samples and $0.6 \%$ for buccal swabs would have only limited effect on enhancing overall sensitivity. Physicians were supplied with ongoing information sheets describing the correct buccal swab technique, but it is possible that there was some suboptimal sampling. The sensitivity of RT-PCR on urine specimens is only $42.6 \%$; the incremental yield by testing urine in addition to a buccal swab in an outbreak setting is low and doubles testing volume and cost.

The value of IgM serology was limited. Although specific (only one false positive was noted in our analysis), it has a sensitivity of only $24.5 \%$ in this population. A recent study comparing the performance of five different mumps IgM EIAs determined the sensitivity of the Enzygnost assay to be $24 \%$ (16). Although the poor sensitivity may be specific to this assay, the sensitivity of the best of the five methods (Microimmune) is only $51 \%$ (16). Early presentation was common during the course of the outbreak, especially when media attention was at its peak. It is possible that the serum was collected too early in the infection. However, an additional 25 sera were submitted for convalescent testing and only one additional case was diagnosed based on seroconversion. More likely, the poor performance of these kits is a reflection of a blunted IgM response in a partially immunized population. Due to the incomplete data regarding vaccination history, a detailed analysis of vaccinated versus nonvaccinated patients is not possible. Of the limited data available, five of eight $(62 \%)$ of laboratory-confirmed cases who did not recall having a mumps vaccine had a positive IgM compared with 17 of 75 (23\%) of cases who recalled being vaccinated against mumps. Although the data are limited and may be subject to recall bias, it does suggest the performance of IgM serology is better in individuals that have not had previous mumps vaccination.
Individuals who have received only one immunization would be considered partially immune and may have a modified response to exposure to natural mumps infection such an atypical presentation, lower level of viral shedding, shorter duration of shedding and a blunted IgM response. When individuals receive a second or booster mumps vaccine, IgM responses are blunted; natural infection in those who received a single vaccine may elicit the same blunted response (17). If used as the sole diagnostic tool, the vast majority of infections will go undiagnosed.

In addition, these partially immunized individuals would have an amnestic B cell response that would allow for the rapid generation of $\mathrm{IgG}$ antibodies when exposed to mumps virus. This might explain why more cases had detectable levels of IgG (88\%) compared with non-cases (69\%). These factors are of particular importance because serology is a common tool used for the diagnosis of mumps infection. Convalescent sera seldom yielded additional positive results and, by its retrospective nature, would offer less assistance in public health management.

Our data suggest that diagnosis based on symptoms alone is not accurate. Of the 3410 RT-PCR specimens from 2082 patients processed from February to July 2007, only 298 (14\%) patients were confirmed as cases by RT-PCR. Although it is clear the predictive value of parotitis alone for the diagnosis of episodic mumps infection is low (18), the predictive value during an outbreak is unknown and laboratory confirmation can sometimes be problematic (19-21). In the UK outbreak in 2004 , only $50 \%$ of the cases identified by general practitioners were confirmed using IgM serology (4).

Few clinicians in NS have recent experience with clinical mumps and its laboratory diagnosis. The clinical spectrum of disease has not been determined in a partially immunized population. It is possible that patients presenting with glandular swelling had conditions other than parotitis. This may have been compounded by the increased publicity in the media and from public health messaging during the outbreak. A 
recent study found that increased media coverage during the mumps outbreak in the UK precipitated an increase in the rates of notification of mumps infection by primary care physicians (22). It is not clear from the study if all of these notifications were subsequently classified as mumps.

Another possibility is the potential co-circulation of other viral pathogens that may mimic mumps infection (23-25). Using serology, Davidkin et al (26) were able to identify a viral cause other than mumps in 84 of 601 Finnish children presenting with low-grade fever and parotid swelling. Although mumps was excluded in these cases on the basis of a negative IgM and given the poor performance of IgM serology, it is possible that some of the remaining 517 cases truly had mumps infection. During our outbreak, parainfluenza, influenza and adenovirus were co-circulating at various times in the community. The possibility that these or other viral causes that could mimic a mumps-like presentation in this cohort is currently under investigation.

The problem with defining a gold standard is a limitation to the present study. There is no gold standard when it comes to mumps diagnosis, particularly in a partially immune population. While a positive culture has high specificity, it is recognized that it lacks sensitivity. The superior sensitivity of RT-PCR makes calculating accurate performance characteristics problematic if culture is used as the reference standard $(13,15)$. This situation is not unique because we have seen similar issues in the early evaluations of molecular diagnostic tests for chlamydia, gonorrhea, influenza and others (27). We chose the PHAC case definition because it is what guides clinicians and public health officials in Canada. However, this approach does have limitations. It can be argued that because this gold standard is a composite of the tests themselves and that the majority of the cases were laboratory confirmed, it may inflate the sensitivity of the individual tests. However, there is no definitive test that might be used to identify patients with negative RT-PCR tests who might have mumps. Recent exposure to a proven case and classical clinical features make mumps likely but our experience suggests that clinicians who have not recently (or who have never) seen a patient with mumps have difficulty with the clinical diagnosis. In addition, the definitive establishment of an epidemiological link to a known case of mumps may be difficult because the person who transmitted the virus may have been asymptomatic or may not have sought medical attention and was therefore never tested. These factors are important to consider when transmission occurs in a public setting. Thus, the PHAC case definition, which relies on subjective clinical assessment, is not perfect. Our results must therefore be analyzed in the absence of a gold standard.

To address this limitation, we also used latent class modelling to obtain diagnostic test properties without reference to an explicit reference standard (28). This statistical technique has been applied to diagnostic areas such as Trypanosoma cruzi serology (29), influenza molecular testing and Chlamydia trachomatis diagnostics (Smieja 2008, unpublished). The method requires three or more diagnostic tests and assumes independent errors conditional on disease status. We could not include clinical diagnosis in our model because this was affected by the diagnostic testing results, and this would violate the criteria for latent class modelling. Latent class modelling has been under-used in diagnostic test evaluation, and may become

\section{TABLE 4}

\section{Laboratory guidelines for the diagnosis of mumps}

Buccal swab for RT-PCR testing collected in the first four days of symptoms is the preferred specimen for diagnosis

IgM serology has poor sensitivity in a partially immunized population

RT-PCR is a reliable and sensitive method for diagnosing mumps infection but results may depend on timing of collection and specimen integrity

No diagnostic test has $100 \%$ sensitivity; thus, a negative test does not rule out mumps infection

Data from reference 8. IgM Immunoglobulin M; RT-PCR Reverse transcriptase polymerase chain reaction

increasingly important to compare culture methods to molecular tests with higher analytic sensitivity. This said, the results using latent class modelling were similar to those obtained using the PHAC case definition. One potential limitation to this approach is the lack of data regarding robust vaccination status, because latent class modelling assumes independent errors conditional on disease status and vaccination status may be an effect modifier and introduce bias.

During the outbreak, a standardized specimen requisition was developed to try and collect a standardized data set and help with triaging when testing volumes became overwhelming. Although some of the gathered information helped verify data collected by the public health officials, the completion of these forms was inconsistent and often vague and unhelpful for triaging. This has highlighted the difficulty with getting frontline clinicians to complete a specific requisition and may help in the development of future standardized requisitions such as ones for use during the time of an influenza pandemic that are currently under development.

The confirmation of mumps in a partially immunized population can be challenging. We showed that RT-PCR, particularly when performed on buccal swabs, is the most sensitive diagnostic test for mumps. The results of IgM testing in our cohort suggest that this test has limited utility, and the addition of a urine specimen to a buccal swab did not substantially increase the number of positive cases. However, because the best laboratory test has a sensitivity of only $79 \%$, laboratory results must be considered in the context of clinical symptoms, timing of specimen collection and epidemiological exposures. Laboratory guidelines have recently been proposed for Canadian clinicians (8). Our data support these recommendations (Table 4).

ACKNOWLEDGEMENTS: The authors would like to thank Dr Graham Tipples for his helpful discussions during this outbreak and to thank Nova Scotia's medical officers of health and the public health nurses and support staff who were instrumental in collecting data and managing the outbreak. Finally, the authors would like to acknowledge the staff of the Division of Microbiology at the Queen Elizabeth II Health Sciences Centre who contributed to work on this outbreak. If it was not for the collective dedication of all of these individuals, none of this work would have been possible. The authors have no conflicts to declare.

\section{REFERENCES}

1. Centers for Disease Control and Prevention. Measles, mumps and rubella - Vaccine use and strategies for elimination of measles, rubella, and congenital rubella syndrome and control of mumps: recommendations of the Advisory Committee on Immunization Practices (ACIP). MMWR Morb Mortal Wkly Rep 1998;47:1-56. 
2. Plotkin SA. Mumps vaccine. In: Plotkin SA, Orenstien WA, eds. Vaccines. Philadelphia: Elsevier, 2004:441-69.

3. National Advisory Committee on Immunization (NACI) Health Canada. Canada Immunization Guide, 6th edn. 2002:166-8.

4. Savage E, White JM, Brown DE, Ramsay ME. Mumps epidemic United Kingdom, 2004-2005. MMWR Morb Mortal Wkly Rep 2006;55:173-5.

5. Dayan GH, Quinlisk MP, Parker AA, et al. Recent resurgence of mumps in the United States. N Engl J Med 2008;358:1580-9.

6. Watson-Creed G, Saunders A, Scott J, Lowe L, Pettipas J, Hatchette TF. Two successive outbreaks of mumps in Nova Scotia among vaccinated adolescents and young adults. CMAJ 2006;175:483-8.

7. Center for Disease Control and Prevention (Atlanta). Mumps specimen collection and management $\mathrm{Q}$ and $\mathrm{A}$. < www.cdc.gov/ vaccines/vpd-vac/mumps/outbreak/faqs-lab-spec-collect.htm> (Version current January 26, 2009).

8. Tipples GA, Beirnes J, Hiebert J, et al. Laboratory guidelines for the diagnosis of mumps v.3 (April 3, 2008). <www.nml-lnm.gc.ca/guide/ guideview-eng.asp?key=186> (Version current January 26, 2008)

9. Jin L, Beard S, Brown DW. Genetic heterogeneity of mumps virus in the United Kingdom: identification of two new genotypes. J Infect Dis 1999;180:829-33.

10. Boddicker JD, Rota PA, Kreman T, et al. Real-time reverse transcription-PCR assay for detection of mumps virus RNA in clinical samples. J Clin Microbiol 2007;45:2902-8.

11. Backhouse JL, Gidding HF, McIntyre PB, Gilbert GL. Evaluation of two enzyme immunoassays for detection of immunoglobulin $G$ antibodies to mumps virus. Clin Vaccine Immunol 2006;13:764-7.

12. Cohen C, White JM, Savage EJ, et al. Vaccine effectiveness estimates, 2004-2005 mumps outbreak, England. Emerg Infect Dis 2007;13:12-7.

13. Krause CH, Eastick K, Ogilvie MM. Real-time PCR for mumps detection on clinical specimens - Comparison with results of conventional methods of virus detection and nested PCR. J Clin Virol 2006;37:184-9.

14. Jin L, Fengt Y, Parry R, Cui A, Lu Y. Real-time PCR and its application to mumps rapid diagnosis. J Med Virol 2007;79:1761-7.

15. Uchida K, Shinohara M, Shimada S, et al. Rapid and sensitive detection of mumps virus RNA directly from clinical samples by realtime PCR. J Med Virol 2005;75:470-4.

16. Krause CH, Molyneaux PJ, Ho-Yen DO, McIntyre P, Carman WF,
Templton KE. Comparison of mumps-IgM ELISAs in acute infection. J Clin Virol 2007;38:153-6.

17. Sanz JC, Mosquera Mdel M, Echevarria JE, et al. Sensitivity and specificity of immunoglobulin $\mathrm{G}$ titer for the diagnosis of mumps virus in infected patients depending on vaccination status. APMIS 2006;114:788-94.

18. DeSerres G, Boulianne N, Bussieres N, Pouliot B, Marin-Lira A. Epidemiology of mumps in Quebec, 1970-1995. Can Comm Dis Rep 1997;23:9-13.

19. Centers for Disease Control and Prevention. Update: Multistate outbreak of mumps - United States, January 1-May 2, 2006. MMWR Morb Mortal Wkly Rep 2006;55:559-63.

20. Castilla J, Garcia Cenoz M, Irisarri F, Nunez-Cordoba JM, Barricarte A. Mumps outbreak in Navarre region, Spain, 2006-2007. Euro Surveill 2007;12:E070215.1.

21. Kojouharova M, Kurchatova A, Marinova L, Georgieva T. Mumps outbreak in Bulgaria, 2007: A preliminary report. Euro Surveill 2007; 12:E070322.4.

22. Olowokure B, Clark L, Elliot AJ, Harding D, Fleming A. Mumps and the media: Changes in the reporting of mumps in response to newspaper coverage. J Epidemiol Community Health 2007;61:385-8.

23. McQuone SJ. Acute viral and bacterial infections of the salivary glands. Otolaryngol Clin N Am 1999;32:793-811.

24. Litman N, Baum SG. Mumps virus. In: Mandell GL, Bennett JE, Dolin R, eds. Principles and Practice of Infectious Diseases, 6th edn. Philadelphia: Elsevier, 2005:2006-207.

25. Battle S, Laudenbach J, Maguire JH. Influenza parotitis: A case from the 2004 to 2005 vaccine shortage. Am J Med Sci 2007;333:215-7.

26. Davidkin I, Jokinen S, Paananen A, Leinikki P, Peltola H. Etiology of mumps-like illness in children and adolescents vaccinated for measles, mumps, and rubella. J Infect Dis 2005;191:719-23.

27. Espy MJ, Uhl JR, Sloan LM, et al. Real-time PCR in clinical microbiology: Applications for routine laboratory testing. Clin Microbiol Rev 2006;19:165-256.

28. Walter SD, Irwig LM. Estimation of test error rates, disease prevalence and relative risk from misclassified data: A review. J Clin Epidemiol 1988;41:923-37.

29. Langhi DM Jr, Bordin JO, Castelo A, Walter SD, Moraes-Souza H, Stumpf RJ. The application of latent class analysis for diagnostic test validation of chronic Trypanosoma cruzi infection in blood donors. Braz J Infect Dis 2002;6:181-7. 


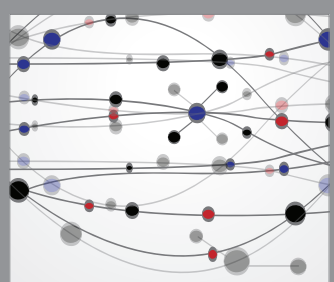

The Scientific World Journal
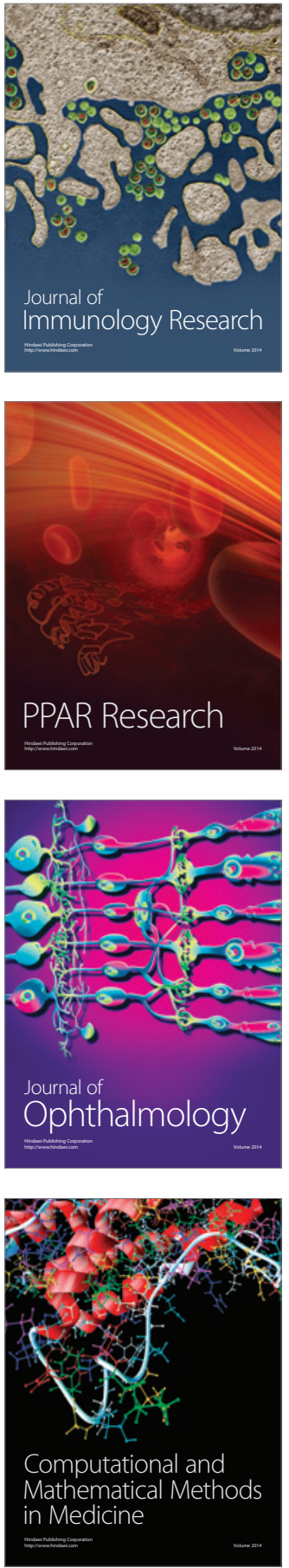

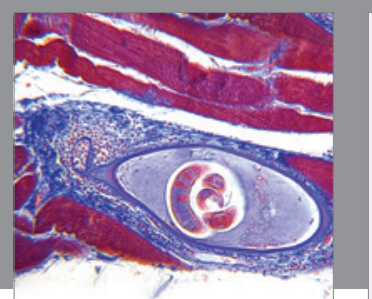

Gastroenterology Research and Practice

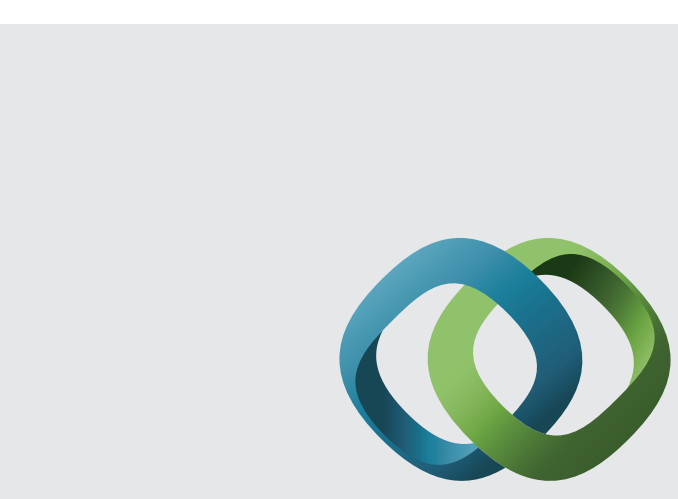

\section{Hindawi}

Submit your manuscripts at

http://www.hindawi.com
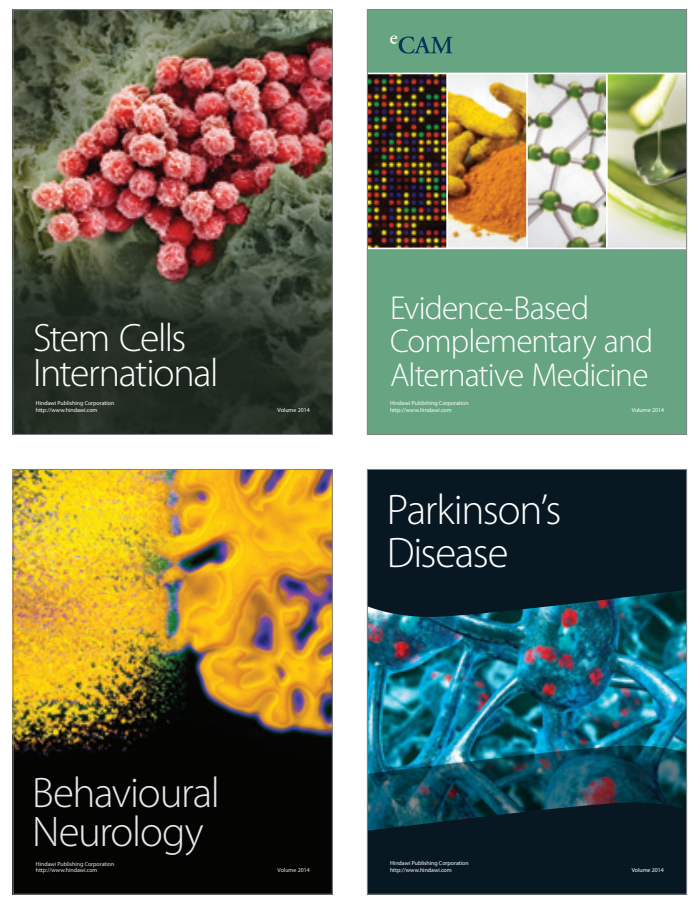
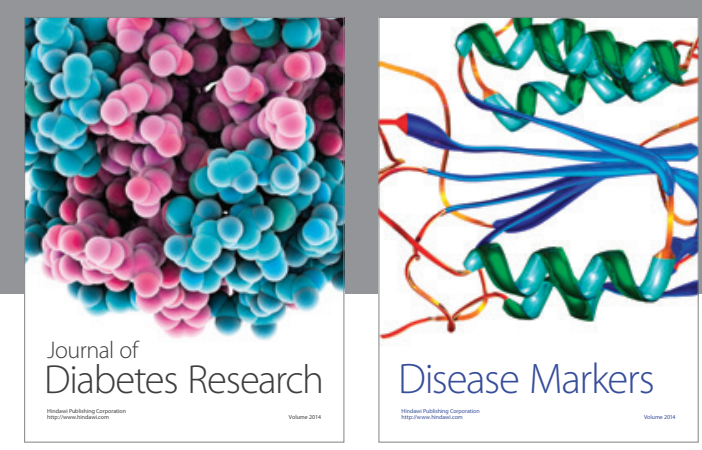

Disease Markers
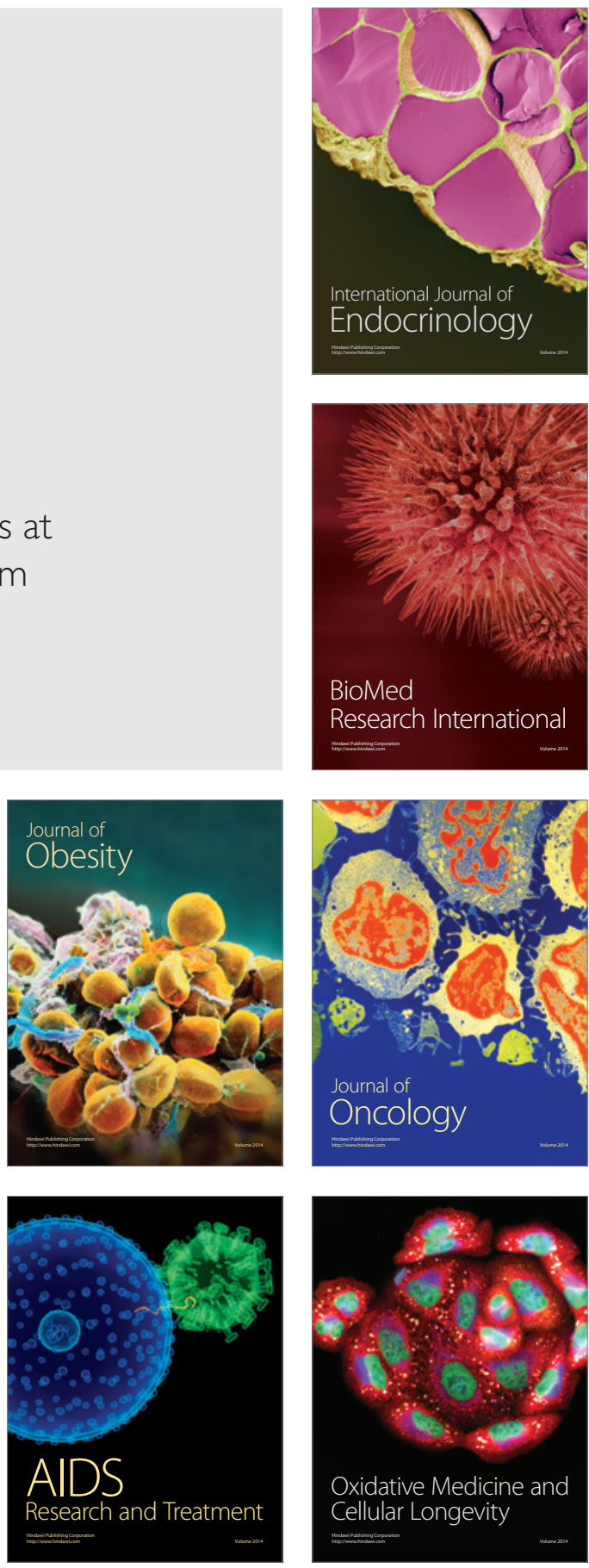